\title{
Research progress of relationship between hyptoxic ischemic encephalopathy and interleukin in neonates
}

\author{
Jianmei Zhang*1, Fasheng $\mathrm{Liu}^{2}$, Xin Chen ${ }^{1}$ \\ ${ }^{1}$ Department of Pediatrics, The Third Affiliated Hospital of Inner Mongolia Medical College, Baotou, China \\ ${ }^{2}$ Department of Medical Laboratory, The Third Affiliated Hospital of Inner Mongolia Medical College, Baotou, China
}

Received: October 20, 2017

DOI: $10.14725 /$ dcc.v4n4p24
Accepted: November 25, $2017 \quad$ Online Published: December 10, 2017

URL: http://dx.doi.org/10.14725/dcc.v4n4p24

\begin{abstract}
Hypoxic ischemic encephalopathy (HIE) refers to brain lesions caused by hypoxia in perinatal neonates, usually combined with damage or dysfunction of other organs. The pathogenesis of HIE is very complex, which is still unclear, and it is one of the important subjects of perinatal medicine research. In recent years, the role of immune system in the pathogenesis of HIE has attracted more and more attention, especially interleukin (IL), which plays an important role in the pathogenesis of HIE. Therefore, further study on the immune mechanism of neonatal HIE, to realize early diagnosis and early intervention is of great significance for preventing HIE complications.
\end{abstract}

Key Words: Hypoxic ischemic encephalopathy, Neonates, Interleukin

Hypoxic ischemic encephalopathy (HIE) is one of the common diseases in perinatal neonates, which mainly refers to hypoxic ischemic brain damage caused by hypoxia in perinatal period. Perinatal hypoxia and ischemia are the most fundamental key factors of HIE, and also the most important cause of brain injury in perinatal neonates. It is possible to die when the disease is aggravated, even if the child who is lucky enough to survive, there will be a series of sequelae, such as neurological dysfunction. ${ }^{[1]}$ HIE can cause nervous system sequelae such as mental retardation, cerebral palsy and seizures, which bring heavy economic burden to family and society. At present, the pathogenesis of HIE is not very clear. It may result from a series of inflammatory chain reactions due to hypoxia and ischemia in neonates, resulting in the change of immune function, especially the release of inflammatory cytokines in vivo, which eventually leads to pathophysiological changes of HIE. Therefore, the change of cytokine plays an important role in its pathological damage. In recent years, the relationship between abnormal immune function and perinatal asphyxia in children with HIE has gradually attracted more attention in this field. ${ }^{[2]}$ The severity of brain damage is highly depended on the condition of HIE. In serious cases, multiple organs could be damaged. Other studies have shown that after reperfusion of cerebral ischemia, HIE was found to reconstitute further injury of reperfusion at the local brain cells, and released a large number of cytokines throughout the whole process. ${ }^{[3]}$ Cytokines are considered to be a class of highly active small molecule proteins produced by some immunoreactive cells and some cells related to immunoreactive cells in vivo. The mononuclear cells in normal human body are rich in various kinds of immunocompetent cells, such as tumor necrosis

\footnotetext{
*Correspondence: Jianmei Zhang; E-mail: zjm168669@126.com; Address: Department of Pediatrics, The Third Affiliated Hospital of Inner Mongolia Medical College, Baotou, China.
} 
factor $\alpha(\mathrm{TNF}-\alpha)$ and various cytokines such as interleukin (IL). Cytokines may be involved in the development process of HIE after asphyxia. The study of cytokines provides an important laboratory diagnostic basis for the diagnosis and treatment of HIE. The relationship between the changes of HIE and IL and its influencing factors is reviewed in our study.

\section{The characteristics of HIE in perinatal neonates}

HIE refers to the brain damage caused by perinatal asphyxia-induced partial or complete anoxia, reduced or sudden stoppage of blood flow in brain tissue, often accompanied by some changes in nervous system pathology and pathophysiology. At the same time, a series of symptoms of encephalopathy occur clinically. According to statistics, the incidence of $\mathrm{HIE}$ is $3 \%-6 \%, 15 \%-20 \%$ of HIE children die in the neonatal period, and $20 \%-30 \%$ in HIE surviving children may leave the sequelae of nervous system in varying degrees in China. ${ }^{[4]}$ After neonatal hypoxia, a series of pathophysiological changes will occur in the body, which eventually leads to irreversible brain tissue damage. The first damage is the energy metabolism of the brain cells, and the effect of HIE on the cerebral blood flow eventually cause the dysfunction of the regulating function of the cerebral vessels. In recent years, it has been found that HIE can induce accelerated apoptosis due to multiple factors. The action of HIE on inflammatory cells and inflammatory factors can cause large aggregation of neutrophils, activated macrophages and microglia in brain tissue. It can be seen that inflammatory cells and many inflammatory cytokines may be involved in the brain tissue damage of HIE. And the study also fully demonstrated that the expression of cytokines related to this process (IL-1, IL- $1 \beta$, IL-6, IL6 mRNA, IL-8 and so on) was significantly increased. The level of IL-6 in CSF of children with HIE is also increased significantly, and is positively correlated with the degree of brain cell injury. The action of multiple cytokines leads to brain cell injury. ${ }^{[5]}$

\section{Relationship between HIE and IL-1 $\beta$}

$\mathrm{IL}-1 \beta$ is mainly secreted by the activated mononuclear phagocyte. It can stimulate a variety of chemotactic cytokine production, which is widely involved in occurrence and development of many diseases. ${ }^{[6]}$ The biological effect of IL- $1 \beta$ is mainly dependent on its combination with target cells and corresponding receptors, and is achieved through a series of complex cellular signal transduction mechanisms. IL- $1 \beta$ is the earliest inflammatory cytokine that occurs after HIE hypoxic ischemic brain damage, and is also the key medium in the immunoregulation of neuroendocrine sys- tem. ${ }^{[7]}$ Patra et al. ${ }^{[8]}$ have found that neonatal hypoxic and ischemic injury is an important cause of perinatal brain damage. Proinflammatory cytokines play an important role in the evolution of this brain injury. IL- $1 \beta$ is the key mediator of the inflammatory response in the brain. The continuous elevated level of IL- $1 \beta$ in the brain can lead to severe neurological dysplasia in children after brain injury. The antiIL-1 $\beta$ monoclonal antibody can effectively prevent the entrance of IL- $1 \beta$ into the blood brain barrier in the fetal sheep with ischemia. Therefore, children with hypoxic-ischemic nervous system development could enjoy the benefit from anti-cytokine therapy. The study results of Ma Z et al. ${ }^{[9]}$ showed that umbilical cord blood mononuclear cell transplantation combined with hyperbaric oxygen therapy could reduce the expression of IL- $1 \beta$ and TNF- $\alpha$ protein, improve the long-term behavioral ability of hypoxic ischemic neonatal rats and alleviate brain damage. In Sadowska's study, ${ }^{[10]}$ proinflammatory cytokines are involved in inflammatory reaction of hypoxic-ischemic brain damage, and blood brain barrier dysfunction is an important part of fetal hypoxicischemic brain damage. In this case, IL- $1 \beta$ passed through the intact fetal blood-brain barrier, and ischemia/reperfusion also enhanced the possibility of cytokines entering into the blood-brain barrier, resulting in brain injury. The IL-1 $\beta$ level of peripheral blood was also detected, and it was found that it could transmit through the nerve medium in the central nervous system of the body. It enters into the brain cells through the damaged blood brain barrier. Microglia and astrocytes of the nervous system in the brain cells are the main factors that contribute to creation of IL- $1 \beta$ factors. Some experiments have shown that the activity of IL- $1 \beta$ in the brain cells of neonatal rats after hypoxic ischemia increased significantly. Moreover, the degree of brain hypoxic and ischemic injury aggravated when the exogenous IL- $1 \beta$ was injected into the ventricle. Studies also found that IL- $1 \beta$ receptor antagonist could significantly reduce the degree of brain damage. ${ }^{[1]}$

\section{Relationship between HIE and IL-6}

IL-6, also known as a proinflammatory cytokine, is involved in various inflammatory processes, such as many kinds of infections, stimulating the growth of other inflammatory cells, promoting the differentiation of inflammatory cells and accelerating the protein synthesis in the acute phase of inflammatory cells. And it plays an important role in the inflammatory response and immune response of the disease. ${ }^{[12]}$ IL-6 is an important cytokine that regulates the anti-infection and defense function of the body, and it has a wide range of biological effects. Some scholars believe that IL-6 is probably the best index to reflect the severity of infection or non-infection stress. ${ }^{[13]}$ Gillani et al. ${ }^{[14]}$ found that IL-6 and IL-18 could play an important role in the inflammatory response of HIE. $\gamma$-aminobutyric acid B-type 
receptor antagonists (CGP 35348 and 55845) can change IL-6 and IL-18 levels in vivo of HIE mice. Orrock et al. ${ }^{[15]}$ also showed that inflammatory cytokines in HIE newborn were significantly increased. In particular, the increase of IL-6 and IL-10 was more obvious, causing certain damage to the nervous system of the newborn. So, early nerve tissue protection and intervention are essential. The increase of serum IL-6, TNF- $\alpha$ and high sensitivity $\mathrm{C}$ reactive protein levels in HIE patients were demonstrated in the study by Shang et al. ${ }^{[16]}$ The increase in the levels of these inflammatory mediators is associated with the severity of the disease, and is also positively related to the prognosis of the disease. $\mathrm{Li}$ et al. showed that inflammatory cytokines, such as TNF$\alpha$ and IL-6, could promote HIE-induced neuronal apoptosis in HIE neonatal rats when reaching the peak injury level for 24-72 $\mathrm{h}$ after brain injury. ${ }^{[17]}$ Iqbal et al. ${ }^{[18]}$ demonstrated that IL-6 had a neuroprotective effect on cerebral ischemia in HIE.

\section{Relationship between HIE and IL-10}

IL-10 is a single chain glycoprotein produced by Th2 cells, and is an inhibitor of cellular immune response. IL-10 can inhibit the secretion of cytokines (IL-1, IL- 6 and TNF- $\alpha$, etc.) from leukocytes and microglia in vitro, but also inhibit the aggregation of leukocytes and the production of chemokines. ${ }^{[19]}$ Moreover, IL-10 can reduce the delayed damage of cerebral ischemia, indicating the neuroprotective effect of IL-10. ${ }^{[20]}$ It has been reported that the apoptosis rate of neurons is positively correlated with the level of TNF- $\alpha$ and IL-6. Inflammatory cytokines TNF- $\alpha$ and IL6 promote HIE-induced neuronal apoptosis, and the rate of neuronal apoptosis is negatively correlated with IL-10 and glial cell line derived neurotrophic factor. In other words, IL-10 and glial cell derived neurotrophic factors can antagonize HIE-induced neuronal apoptosis. ${ }^{[17]}$

Brain injury includes trauma, infection and perinatal injury, for example, HIE can produce inflammation in the brain. Cytokines can not only promote the occurrence of inflammation, but also resist it. IL-1 $\beta$ and IL-8 are proinflammatory cytokines, which can activate extra cytokines and increase seizure susceptibility and organ damage. IL-1 receptor antagonists and IL-10 as anti-inflammatory cytokines play a protective and anticonvulsant role in brain tissue. ${ }^{[21]}$ Liu KY et al. ${ }^{[22]}$ showed that the changes in serum IL-10 level in children with HIE were closely related to the condition of the disease. That is to say, the serum IL-10 level in acute phase is significantly higher than that in recovery stage. The more severe the disease is, the higher serum IL-10 level would be. With the improvement of HIE condition, serum IL-10 level gradually returns to normal level. At the same time, the changes of serum IL-10 and monocyte chemoattractant protein 1 were found to be synergistic. Therefore, detection of changes in serum IL-10 and mono- cyte chemoattractant protein 1 can be used as a laboratory indicator to determine the efficacy of HIE and the severity of the disease in time. Moon et al. ${ }^{[23]}$ explored the changes in cytokines in the HIE newborn with low temperature treatment. The results showed that the level of cytokine IL-6 in the normal temperature group was significantly higher than that in the low temperature group, but the level of cytokine IL-10 was significantly higher than that in the normal temperature group. This indicates that hypothermia plays an important role in preventing the process of inflammation. It can maintain low level of cytokine IL-6 in the body, and keep the anti-inflammatory IL-10 at a high level.

\section{Relationship between HIE and IL-18}

IL-18 is a pleiotropic cytokine. It plays an important role in the immune response of body cells and the regulation of various physiological functions under normal condition. The biological activity of IL-18 is varied, whose main function is to release the activity of pro-inflammatory factor and impose its potential inflammatory effect. ${ }^{[24]}$ IL-18 is closely related to the occurrence of hypoxic ischemic brain damage caused by perinatal asphyxia. IL-18, as an anti-inflammatory cytokine, protects the brain, while it also causes damage to the brain at the same time as a kind of inflammatory cytokine. ${ }^{[25]}$ Sumanovic-Glamuzina et al. ${ }^{[26]}$ found that the determination of serum IL-6, TNF- $\alpha$ and IL-18 levels could reflect the severity and prognosis of HIE in children compared with cerebrospinal fluid. Liu CQ et al. ${ }^{[27]}$ showed that selective head mild hypothermia treatment for HIE neonates can inhibit the release of Caspase- 3 and the expression of IL-18 in moderate and severe HIE of neonates. It proves that hypothermia cooling can protect neonates from HIE damage.

Yang MH et al. ${ }^{[28]}$ reported that the expression level of IL18 in children with moderate and severe HIE was higher than that in mild group. The expression level of IL-18 is related to the severity of the disease. That is, the more the brain cells are hypoxic and ischemia, the more severe the brain edema and brain cells are, the more obvious the expression of IL-18 is. The up-regulation of IL-18 after HIE suggests that it is involved in the HIE pathological process and inflammatory reaction of immature brain cells, and the reasonable intervention of its expression and activity may inhibit the excessive inflammatory reaction. Inflammation is an important factor in HIE. IL-18 is a pro-inflammatory cytokine, which may be one of the reasons for the injury of immature brain after HIE. The study found that the treatment of hypothermia after HIE could reduce the level of IL-18 mRNA and protein. At the same time, hypothermia therapy after HIE may also reduce the activation of small neuroglia in the brain development of the child. ${ }^{[29]}$ 


\section{Relationship between HIE and other ILs}

During the 6 months after birth, the serum IL- $1 \beta$, IL- 6 , IL-8 and IL-1Ra increased significantly in HIE children, which fully reflected the severity of HIE in children with brain injury. Moreover, the obvious elevation of IL- 8 can be used as a biological marker for the prognosis of early HIE brain injury, which is easy to occur in neonatal convulsion. ${ }^{[30]}$ Quiniou et al. ${ }^{[31]}$ confirmed the leading role of IL-1 in hypoxicischemic brain damage as an important proinflammatory cytokine. It is involved in the whole process of the occurrence and development of hypoxic-ischemic brain damage. Some studies also demonstrate that IL-1 plays its functions by interacting with the IL-1 receptor. IL-1 receptor antagonist can compete with IL-1 to combine IL-1 receptor and block the activity of IL-1, thus reducing the IL- $1 \beta$ mediated cerebral ischemia/reperfusion injury. ${ }^{[32,33]}$ In vivo and in vitro studies of Girard ${ }^{[34]}$ showed that the level of IL-2 mRNA and protein increased significantly and the $\mathrm{T}$ lymphocyte decreased significantly during the hypoxic-ischemic brain injury. The expression level of $\mathrm{T}$ lymphocyte subsets and membrane IL-2 receptor in serum of children with HIE was observed by IL-1 receptor antagonism in Wang and Lu's research. ${ }^{[35]}$ Walsh et al. ${ }^{[36]}$ explored the relationship between multiple umbilical cord blood proteins and the severity of HIE by using continuous multi-channel electroencephalography. The results showed that IL- 6 and IL-16 in umbilical cord blood were related to the electroencephalogram classification of HIE. The combination of IL-16 and the Apgar

\section{References}

[1] Mei H, Liu CZ, Zhang YY. Changes of serum cytokines and T cell subsets in neonates with hypoxic-ischemic encephalopathy. Chinese Journal of Neonatology. 2011; 26(6): 403-405.

[2] Celik Y, Atc A, Gulas, S, et al. The effects of selective head cooling versus whole-body cooling on some neural and inflammatory biomarkers: A randomized controlled pilot study. Ital J Pediatr. 2015; 15(41): 79. PMid: 26472263. https://doi.org/10. 1186/s13052-015-0188-5

[3] Mei H, Liu CZ, Zhang YY. Expression of cytokines in neonates with hypoxic ischemic encephalopathy. Inner Mongolia Medical Journal. 2011; 43(12): 1417-1419.

[4] Wang WP. Pediatrics. $8^{\text {th }}$ edition. Beijing: People's medical publishing house; 2013. 107-109 p.

[5] Shao XM, Ye HM, Qiu XS. Practice of Neonatology. $4^{\text {th }}$ edition. Beijing: People's medical publishing house; 2011. 699-704 p.

[6] Sumagin R, Lomakina E, Sarelius IH, et al. Leukocyte endothelial cell interactions are linked to vascular permeability via ICAM 1-mediated signaling. Am J Physiol Heart Circ Physiol. 2008; 295(3): 969-977. PMid: 18641276. https://doi.org/10.1152/ ajpheart.00400.2008

[7] Liu J, Feng ZC. Increased umbilical cord plasma interleukin-1 beta levels was correlated with adverse outcomes of neonatal hypoxicischemic encephalopathy. J Trop Pediatr. 2010; 56(3): 178-182. PMid: 19822562. https://doi.org/10.1093/tropej/fmp098

[8] Patra A, Chen X, Sadowska GB, et al. Neutralizing anti-interleukin$1 \beta$ antibodies reduce ischemia-related interleukin- $1 \beta$ transport score after the birth of the newborn at 10 min can predict the occurrence of abnormal EEG. The study results of $\mathrm{Wu}$ $\mathrm{XB}$ et al. ${ }^{[37]}$ showed that the serum levels of IL-17 and IL23 in the moderate and severe HIE group were significantly higher than those in the normal control group. There is imbalance in the expression of cytokines in peripheral blood of children with HIE. Detection of peripheral blood regulatory T cells and Th17 and cytokines level has certain clinical significance in judging the progress of HIE and guiding clinical treatment.

\section{Conclusions}

HIE is a common disease of the newborns. The pathogenesis of HIE is very complex, which is still unclear, and it is one of the important subjects of perinatal medicine research. In recent years, the relationship between cytokine and HIE has become a hot topic. Vivo and vitro studies confirm that some cytokines, especially ILs mediate and participate in the pathological process of hypoxic-ischemic brain damage, and play an important role in the occurrence and development of HIE. These studies provide a new theoretical basis for further elucidating the pathogenesis of HIE and to explore the way of clinical immunotherapy.

\section{Conflicts of Interest Disclosure}

The authors have no conflicts of interest related to this article.

across the blood-brain barrier in fetal sheep. Neuroseience. 2017; 9(346): 113-125. PMid: 28089577.

[9] Ma Z, Yan SZ, Wang XL, et al. Effect of umbilical cord blood mononuclear cell transplantation combined with hyperbaric oxygen therapy on hypoxic and ischemic brain injury in neonatal rats. Chin J Contemp Pediatr. 2015; 17(7): 736-740.

[10] Sadowska GB, Chen X, Zhang J, et al. interleukin-1 $\beta$ transfer across the blood-brain barrier in the ovine fetus. J Cereb Blood Flow Metab. 2015; 35(9): 1388-1395. PMid: 26082012. https://doi.org/ $10.1038 / j \mathrm{cbfm} .2015 .134$

[11] Wixey JA, Reinebrant HE, Spencer SJ, et al. Efficacy of post-insult minocycline administration to alter long-term hypoxia-ischemiainduced damage to the serotonergic system in the immature rat brain. Neuroscience. 2011; 19: 184-192. PMid: 21440046. https : //doi.org/10.1016/j.neuroscience.2011.03.033

[12] Xu ML, Yang CY, Chen HQ. Research progress of interleukin-6 in early diagnosis of neonatal infectious diseases. Chinese Journal of Neonatology. 2012; 27(2): 131-134.

[13] Adib-conquy M, Cavaillon JM. Stress molecules in sepsis and systemic inflammatory response syndrome. FEBS Lett. 2007; 581(19): 3723-3733. PMid: 17428476. https://doi.org/10.1016/j. febslet.2007.03.074

[14] Gillani Q, Ali M, Igbal F. Effect of CABAB receptor antagonists (CGP 35348 and CCP 55845) on serum interleukin 6 and 18 concentrations in albino mice following neonatal hypoxia ischemia insult. Pak J Pharm Sci. 2016; 29(5): 1503-1508. PMid: 27731803.

[15] Orrock JE, Panchapakesan K, Vezina G, et al. Association of brain injury and neonatal cytokine response during therapeutic hypothermia in newboms with hypoxic-ischemic encephalopathy. Pediatr 
Res. 2016; 79(5): 742-747. PMid: 26717001. https ://doi.org/ $10.1038 / \mathrm{pr} .2015 .280$

[16] Shang Y, Mu L, Guo X, et al. Clinical signifieance of interleukin6 , tumor necrosis factor- $\alpha$ and high-sensitivity C-reactive protein in neonates with hypoxic-ischemic encephalopathy. Exp Ther Med. 2014; 8(4): 1259-1262. PMid: 25187835. https://doi.org/10. 3892/etm. 2014.1869

[17] Li SJ, Liu W, Wang JL, et al. The role of TNF- $\alpha$, IL-6, IL-10 and GDNF in neuronal apoptosis in neonatal rat with hypoxic-ischemic encephalopathy. Eur Rev Med Pharmacol Sci. 2014; 18(6): 905-909. PMid: 24706318.

[18] Iqbal S, Ali M, Iqbal F. Effect of creatine monohydrate supplementation on relative serum level of IL-6 and IL-18 following neonatal hypoxia ischemia in male albino mouse. Pak J Pharm Sei. 2015; 28(6): 2141-2145. PMid: 26639507.

[19] Anderson KF, Lonsway DR, Rasheed JK. et al. Evaluation of methods to identify the Klebsiella pneumoniae carbapenemase in Enterobacteriaceae. J Clin Microbiol. 2007; 45(8): 2723-2725. PMid: 17581941. https://doi.org/10.1128/JCM.00015-07

[20] Li JZ, Liu LP. Progress in the research of KPC carbapenem and its detection. Int J Lab Med. 2010; 31(4): 357-359.

[21] Youn Y, Sung IK, Lee IG. The role of cytokines in seizures: Interleukin(IL)-1 $\beta$, IL-1Ra, IL-8, and IL-10. Korean J Pediatr. 2013; 56(7): 271-274. PMid: 23908665. https://doi.org/10.3345/ kjp.2013.56.7.271

[22] Liu KY, Zhang ZM, Song QY, et al. Changes and clinical significance of serum IL-10 and MCP-1 in neonates with hypoxic ischemic encephalopathy. Chinese Journal of Difficult and Complicated Cases. 2011; 10(1): 13-15.

[23] Moon CJ, Youn YA, Yum SK, et al. Cytokine changes in newborns with therapeutic hypothermia after hypoxic ischemic encephalopathy. J Perinatol. 2016; 36(12): 1092-1096. PMid: 27583390. https://doi.org/10.1038/jp. 2016.132

[24] Kan XM, Yang MH, Wei XM, et al. The correlation between serum IL-18 and hsCRP in children with hypoxic-ischemic encephalopathy. Chinese Primary Health Care. 2011; 25(7): 68-69.

[25] Feng YS. Clinical significance of changes in serum IL-8 and IL-18 and adiponectin levels in children with HIE. Zhejiang Clinical Medical Journal. 2012; 14(11): 1443-1444.

[26] Sumanovic-Glamuzina D, Culo F, Culo MI, et al. A comparison of blood and cerebrospinal fluid cytokines (IL-1 $\beta$, IL-6, IL-18, TNF$\alpha$ ) in neonates with perinatal hypoxia. Bosn J Basic Med Sci. 2017; 17(3): 1381.
[27] Liu CQ, Xia YF, Yuan YX, et al. Effect of mild hypothermia on cysteine protease-3 and interleukin-18 in neonates with hypoxic ischemic encephalopathy. Chin J Contemp Pediatr. 2010; 12(9): 690692.

[28] Yang MH, Kan XM, Li YY, et al. Changes and clinical significance of serum cytokines in neonates with HIE. Int J Lab Med. 2011; 32(16): 1814-1815.

[29] Fukui O, Kinugasa Y, Fukuda A, et al. post-ischemic hypothermia reduced IL-18 expression and suppressed microglial activation in the immature brain. Brain Res. 2006; 1121(1): 35-45. PMid: 17010950. https://doi.org/10.1016/j.brainres . 2006.08.121

[30] Youn YA, Kim SJ, Sung IK, et al. Serial examination of serum IL-8, IL-10 and IL-1Ra levels is significant in neonatal seizures induced by hypoxic-ischaemic encephalopathy. Scand J Immunol. 2012; 76(3): 286-293. PMid: 22537067. https://doi.org/10. $1111 / j .1365-3083.2012 .02710 . x$

[31] Quiniou C, Kooli E, Joyal JS, et al. interleukin-1 and ischemic brain injury in the newbom: Development of a small molecule inhibitor of IL-1 receptor. Semin Perinatol. 2008; 32(5): 325-333. PMid: 18929155. https://doi.org/10.1053/j.semperi.2008.07. 001

[32] Yang MH, Lu F, Guan XR, et al. Changes and clinical significance of serum interleukin-1 receptor antagonist and hypersensitive $\mathrm{C}$ reactive protein in neonates with hypoxic-ischemic encephalopathy. Chin J Perinat Med. 2010; 13(1): 60-62.

[33] Cheng ZZ, Tian L, Zheng XY. Significance of changes in serum levels of interleukin-1 receptor antagonist and high sensitive $C$ reactive protein in neonates with hypoxic-ischemic encephalopathy. Chinese Journal of Applied Clinical Pediatrics. 2012; 27(24): 1881-1882.

[34] Girard S, Larouche A, Kadhim H, et al. Lipopolysaccharide and hypoxia/ischemia induced IL-2 expression by microglia in neonatal brain. Neuroreport. 2008; 19(10): 997-1002.

[35] Wang J, Lu Q. Expression of T subsets and mIL-2R in periphera blood of newborns with hypoxic ischemic encephalopathy. World J Pediatr. 2008; 4(2): 140-144. PMid: 18661772. https://doi. org/10.1007/s12519-008-0028-4

[36] Walsh BH, Boylan GB, Livingstone V, et al. Cord blood proteins and multichannel-electroencephalography in hypoxicischemic encephalopathy. Pediatr Crit Care Med. 2013; 14(6): 621-630. PMid: 23823198. https://doi.org/10.1097/PCC. ob013e318291793f

[37] Wu XB, Fan JT, Shen XD, et al. Changes in the levels of regulatory $\mathrm{T}$ cells and auxiliary $\mathrm{T}$ cells 17 and their cytokine levels in peripheral blood of children with hypoxic ischemic encephalopathy. J Xinxiang Med Coll. 2015; 32(1): 38-40. 